\title{
REDUCTION AND DISTRIBUTION OF LATERAL SEISMIC INERTIA FORCES ON BASE ISOLATED MULTISTOREY STRUCTURES
}

\author{
Takim Andriono* \& Athol J. Carr* *
}

\begin{abstract}
This paper presents some important results of a thorough investigation into the seismic behaviour of a wide range of Base Isolated multistorey structures. The benefits of implementing BI systems are highlighted. The reduction and distribution patterns of lateral inertia forces due to the inclusion of this isolation system are specifically discussed.
\end{abstract}

\section{INTRODUCTION}

During the last two decades the Base Isolation (BI) technique has gained increasing recognition as indicated by the application of various BI systems to a large number of bridges, several multistorey buildings and some power plants in countries which have high seismic risk. In New Zealand alone there are more than 20 Base Isolated (BI) bridges and three BI multistorey buildings, namely the William clayton Building in Wellington [1], Union House in Auckland [2] and the Wellington Police Headquarters [3].

Many practical BI schemes, such as leadrubber bearings and combination of sleeved piles or elastomeric bearings plus mildsteel energy dissipators or lead-extrusion dampers, have been developed and used in recent years. It is believed that interest in the application of this technique will continue to grow. Unfortunately the currently available design procedures, especially BI multistorey structures, seem inadequate and too restrictive [4]. As a result the design practice at present still relies upon a series of deterministic time history analyses with direct step-by-step integration which are not only impractical for design purposes but appear unable to give the designer a clear insight into the seismic behaviour of BI multistorey structures. It is understood that without a clear insight a structural designer will not be able to present an optimum design.
Realizing the above need, research was carried out at the University of Canterbury [4]. Its first objective was into BI multi-storey structures to review the short-comings of current design methods and to investigate in more detail the seismic behaviour of a wide variety of BI multistorey structures. Then, based on the results obtained, the above research was directed to accomplish its second objective which is to develop a simple design procedure for this type of structure.

In this paper some important results of the above investigation are presented. The reduction and distribution patterns of lateral inertia forces due to the implementation of BI systems are specifically discussed. In Sections 3 and 4 , a single ground motion namely the EI Centro $1940 \mathrm{~N}-\mathrm{S}$ earthquake is considered while in section 5, the effect of different ground motions is also discussed. A proposed design approach is described in an accompanying paper $(5)$.

\section{ESSENTIAL CHARACTERISTICS AND BASIC PRINCIPLES}

A desirable BI system should embody several essential characteristics.

(a) Horizontal flexibility which is able to lengthen the fundamental natural period of the structure. Under earthquakes with acceleration response spectra that diminish at University of Canterbury) (Member, NZNSEE)

** Reader in Civil Engineering, University of Canterbury (Fellow, MNZNSEE) 
longer natural periods, this action will shift the structure out from the dominant earthquake energy region and thus will significantly reduce the inertia forces induced in the superstructure.

(b) The capability of dissipating earthquake energy so as to resist excessive horizontal displacements at the base of the building. This additional hysteretic damping will reduce further the spectral acceleration and hence the forces. Fig. 1 shows the reduction of spectral acceleration due to the fundamental period shift and the additional hysteretic damping.

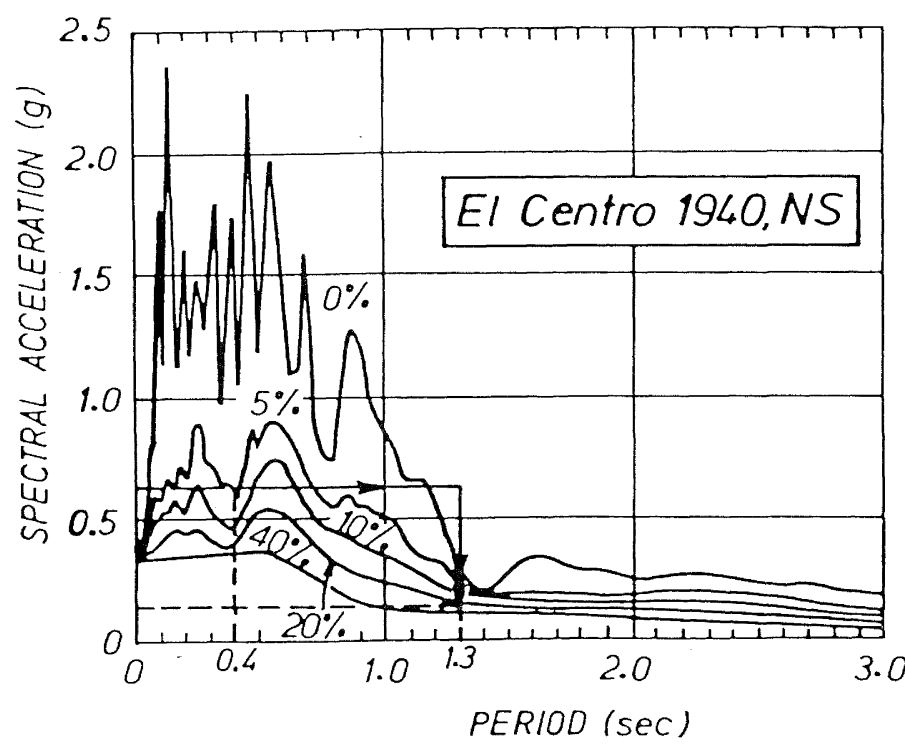

FIGURE 1: REDUCTION OF SPECTRAI ACCELERATION DUE TO PERIOD SHIFT AND ADDITIONAL DAMPING

(c) A so-called mechanical fuse which will guarantee sufficient stiffness of the structure at the service lateral load levels such as occur with wind and micro-tremors but which softens with high seismic accelerations.

(d) Sufficient restoring force to relocate the structure near its original position after an earthquake attack. The isolation system should also provide sufficient vertical stiffness to transfer the vertical loads without differential settlement or unexpected rocking mechanisms.

(e) Is cheap, easily constructed and replaced, not susceptible to fatigue effects under ambient loading and requires minimal maintenance during its effective life.

For design purposes it is important to be able to measure the effective stiffness

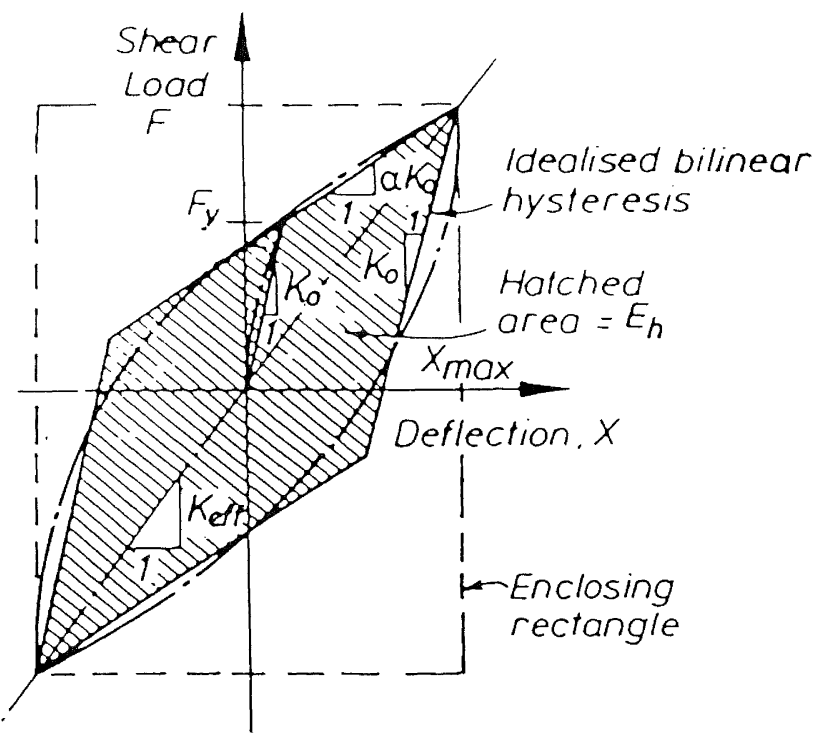

FIGURE 2: A TYPICAL HYSTERSIS LOOP OF A BI SYSTEM AND ITS IDEALISED BILINEAR HYSTERESIS

$\mathrm{k}_{\text {eff }}$ and the additional hysteretic damping, $\mathrm{E}_{\mathrm{h}}$ of the $\mathrm{BI}$ system at the maximum displacement, $x_{\max } \cdot \quad$ Fig.2 illustrates $a$ typical hysteresis loop model. The initial and unloading stiffness is denoted by $k_{0}$ whereas the post-yield stiffness is expressed by $\alpha \mathrm{k}_{0}$. $\mathrm{F}_{\mathrm{y}}$ denotes the yield force of the BI system which is reached at the yield displacement, $\mathrm{x}_{\mathrm{y}}$.

This study assumes $K_{\text {eff }}$ to be the secant stiffness at $x_{\max }$ and $\mathrm{E}_{\mathrm{h}}$ is estimated from the area circumscribed by the hysteresis loop. These two parameters, $\mathrm{k}_{\text {eff }}$ and $\mathrm{E}_{\mathrm{h}}$ can be expressed in the following equations in terms of the initial stiffness, $k_{0} ;$ the ratio of the post-yield stiffness to the initial stiffness, $\alpha_{i}$ and the ratio of the maximum displacement to the yield displacement, $\mu$.

$$
\begin{gathered}
\mathrm{k}_{\text {eff }}=\mathrm{k}_{\circ}\left(\frac{1-\alpha}{\mu}+\alpha\right) \\
\mathrm{E}_{\mathrm{h}}=\frac{2}{\pi} \mathrm{R}
\end{gathered}
$$

where

$$
\mathrm{R}=(1-\alpha)\left(\frac{\mu-1}{\mu^{2}}\right) \frac{\mathrm{k}_{\mathrm{o}}}{\mathrm{k}_{\mathrm{eff}}}
$$

Factor $\mathrm{R}$ expressed in Eq.3 is the ratio of the bilinear hysteresis loop area to the area of its enclosing rectangle. It is useful to introduce this factor since the fatness of the hysteresis loop can be estimated directly from it. $R$ may vary from zero for a linear BI system to almost one for a very fat hysteresis loop.

\section{EVALUATION OF THE SEISMIC RESPONSE}

The implementation of a BI system is meant to protect a structure from the seismic 
damage by concentrating the inelastic deformations to relatively cheap and replaceable devices and by ensuring that, as far as possible, the rest of the structure remains elastic. It is reasonable therefore to investigate first of all the seismic behaviour of Base Isolated multistorey structures with elastic superstructures.

Extensive inelastic time history analyses have been carried out for the above purpose using the computer program RUAUMOKO ${ }^{(6)}$ which is based on a direct time-integration. In the two following parts of this section the influence of three important structural parameters on the seismic response of BI multistorey buildings with elastic superstructures are discussed. The three parameters are :

(a) the fundamental period of the superstructure on an equivalent fixed-base or Unisolated condition, $\mathrm{T}_{1(\mathrm{UI})} \cdot$

(b) the initial stiffness, $k_{0}$, the postyield stiffness, $\alpha \mathrm{k}$ and the yield strength, $F_{y}$ of the $B I$ system.

(c) the frame action or the type of the superstructure which can be expressed in its joint-rotation index, $\epsilon$, as defined by Blume [7] and which is based on the properties of beams and columns in the storey closest to the mid-height of the frame :

$$
\rho=\frac{\sum_{\text {beam }} E I_{b} / L_{b}}{\sum_{\text {column }} E I_{C} / L_{c}}
$$

where $E$ is the elastic modulus of the structural materials, $I_{b}$ and $I_{c}$ are the beam and column moments of inertia, $I_{b}$ and $\mathrm{L}_{\mathrm{C}}$ are the length of the beam and column respectively. Note a complete range of frame behaviour can be covered by simply varying $\epsilon$ from $\epsilon=0.0$ for flexural "cantilever-beam" structures, in which the beams impose no restraint on joint rotation, to the "shear-beam" structures, where the joint rotation are completely restrained $(\epsilon=\infty)$.

At the end of this section the effect of BI system on the inelastic response of the superstructure will be discussed briefly.

\subsection{Lateral storey Displacements}

The typical lateral displacements of a four-storey uniform "shear beam" model with and without BI system are contrasted in Fig.3. In BI multistorey structures larger displacements should be expected due to the horizontal flexibility provided by the BI system. To avoid contact with adjacent buildings during earthquakes, a sufficient gap must be provided to accommodate these large lateral displacements. Also flexible connections should be provided for services, such as water supply, drainage system, etc., into the building.

It is worth noting that the base of a BI $m$ : Floor mass

$k$ : Storey stiffness

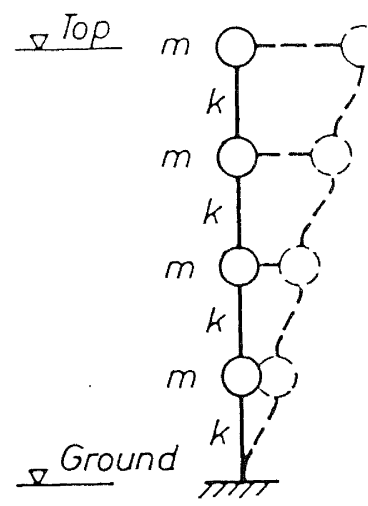

(a) Fixed-Base (b) Base Isolated

FIGURE 3: TYPICAL LATERAL DISPLACEMENTS OF A MULTISTOREY UNIFORM STRUCTURE WITH AND WITHOUT BI SYSTEM

structure moves in the horizontal direction as much as the top floor. Thus, there is a significant reduction in the interstorey drift which will considerably limit the damage to non-structural elements, such as partitions, plasterings, veneers, windows and equipment installed within the building. Furthermore they imply reduced force response in the structural members. These benefits will offset the disadvantages caused by the larger lateral movements.

The influence of the fundamental period the superstructure, $\mathrm{T}_{1}$ (UI) on the maximum lateral storey displacements is shown in Fig.4. In this case the BI system has $\mathrm{k}_{0}=$ $10.0 \mathrm{~W} / \mathrm{m}, \alpha \mathrm{k}_{0}=1.5 \mathrm{~W} / \mathrm{m}$ and $\mathrm{F}_{\mathrm{y}}=5 \% \mathrm{~W}$, where $W$ is the total weight of the structure. As expected, flexible unisolated structures (with relatively long $\mathrm{T}_{1 \text { (UI) have greater storey }}$ displacements than the stiffer ones. similar performance is also shown by BI structures with respect to their base displacements. However, the storey displacements of a BI structure relative to the base movement are much smaller when compared with the storey displacements of unisolated structures.

With regard to the influence of $T_{1}$ (UI) on the interstorey drifts, it was found from the response history that the interstorey drifts of BI multistorey structures with stiff superstructures (say $\mathrm{T}_{1 \text { (UI) }}=0.2$ secs) are always in phase with each other revealing the dominance of the first mode. The drifts between the ground and first floors are always the maximum and followed in sequence by the drifts of the higher storeys in an almost constant ratio. As the superstructure becomes more flexible, however, the interstorey drifts are no longer in phase due to the effect of the higher modes. The maximum drifts may no longer occur in the first storey. In an elastic unisolated structure this 


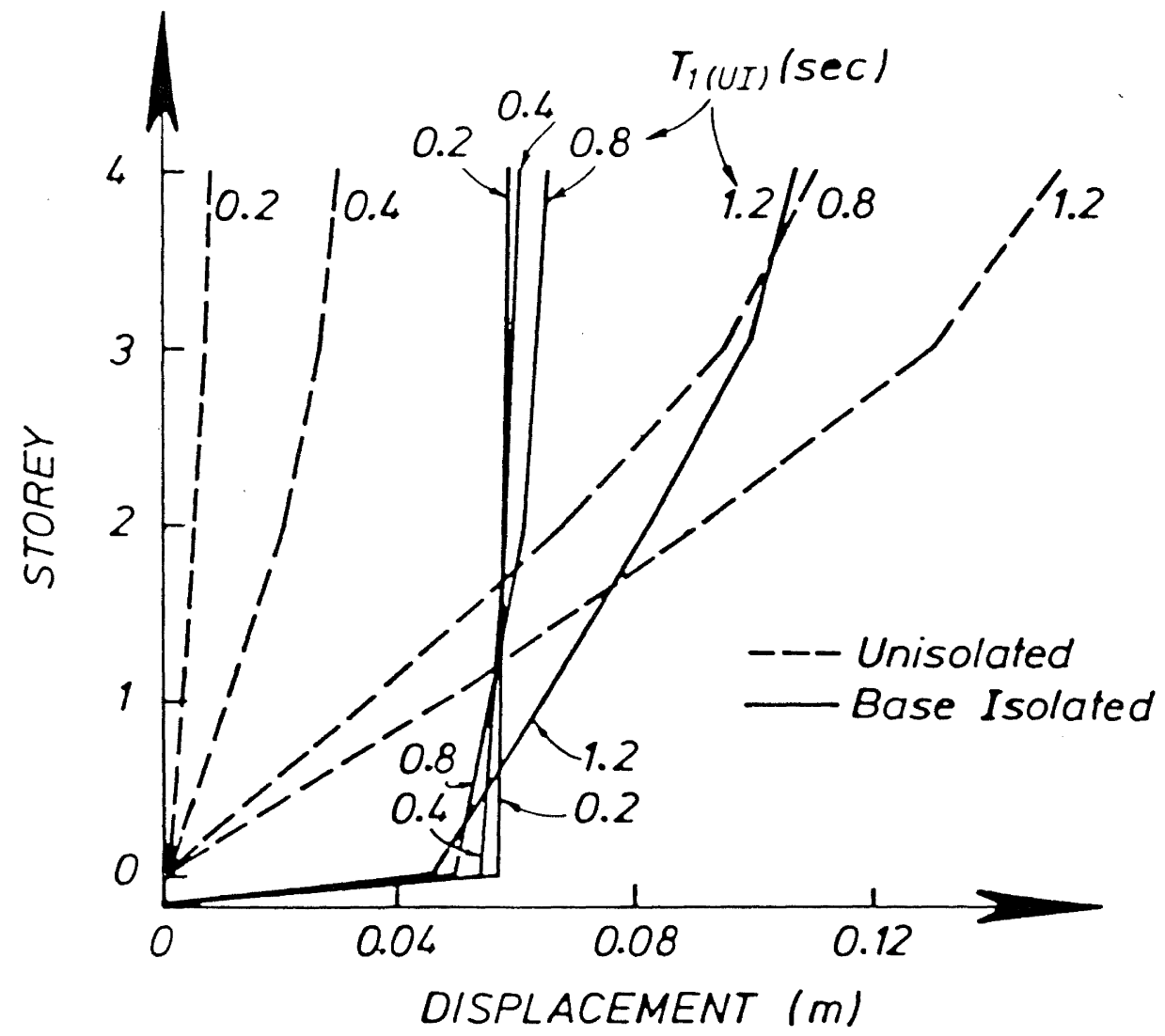

FIGURE 4: MAXIMUM STOREY DISPLACEMENTS OF UNISOLATED AND BI MULTISTOREY STRUCTURES WITH VARIOUS $T_{1 \text { (UI) }}$

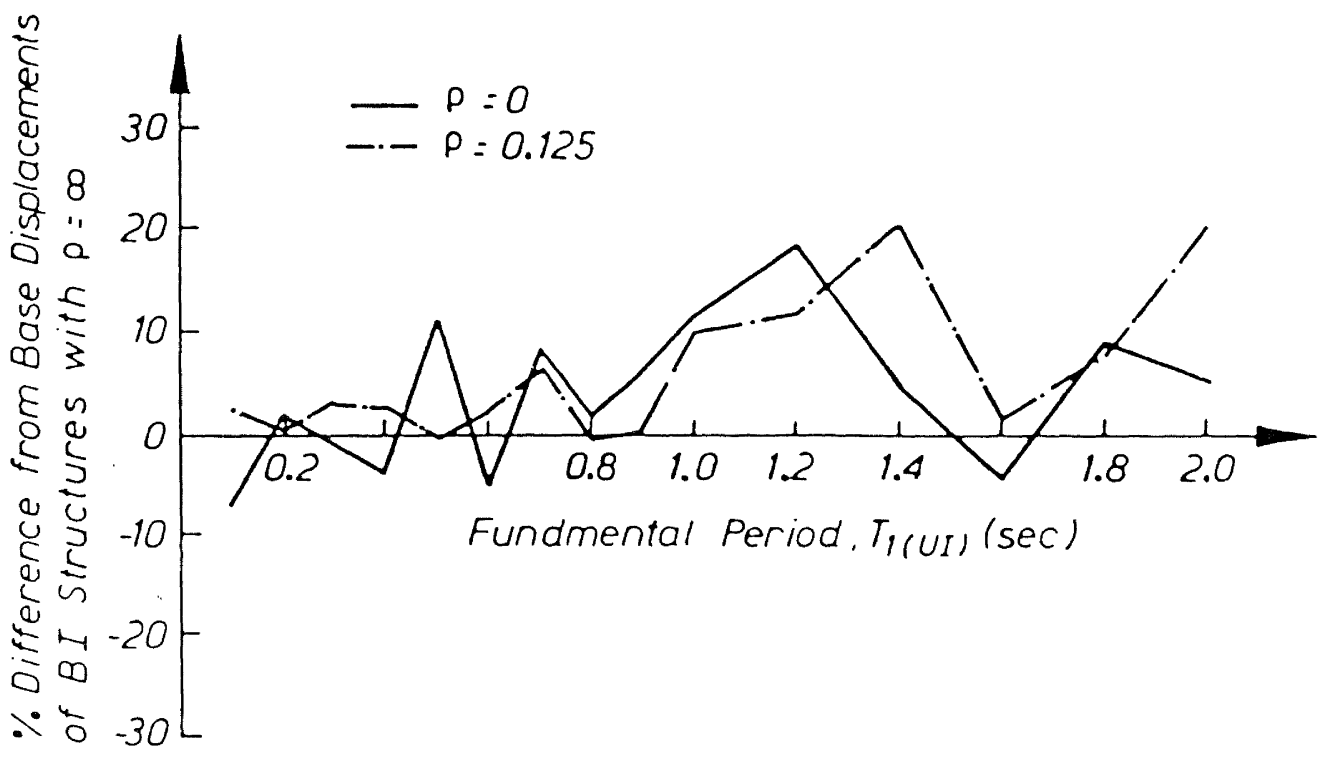

FIGURE 5: MAXIMUM BASE DISPLACEMENTS OF BI STRUCTURES WITH DIFFERENT $\mathrm{T}_{1(\mathrm{UI})}$ AND $\epsilon$ 
difference of behaviour is much less visible.

The above phenomenon can be easily overlooked since the interstorey drifts of a BI structure are much smaller when compared to its base displacement. The superstructure seems to move like a "rigid body" on top of a "spring" with a large horizontal flexibility.

Although the other two structural parameters, namely the frame action and the BI system's parameters may also have significant effects on the interstorey drifts the phenomena will be discussed implicitly while discussing the distribution patterns of the lateral inertia forces. In the following only the effects of those parameters on base displacement will be discussed.

Figure 5 shows that the difference in maximum base displacement as affected by superstructure type are not significant especially for BI structures with $\mathrm{T}_{1\langle\text { UI }} \leq$ 0.8 secs. Within this range the base displacements of BI structures with $\epsilon=0.0$ ("cantilever-beam") and $\epsilon=0.125$ ("typical moment resisting frame") differ less than $12 \%$ when compared to the base displacements of BI "shear-beam" structures $(\epsilon=\infty)$. For the whole considered range of $\mathrm{T}_{1}$ (UI), i.e. up to 2.0 seconds, the differences are less than $21 \%$.

In the above evaluation all structures are mounted on a BI system with a fixed-set of parameters, namely $\mathrm{k}_{0}=10.0 \mathrm{~W} / \mathrm{m}, \alpha \mathrm{k}_{0}=1.5$ $\mathrm{W} / \mathrm{m}$ and $\mathrm{F}_{\mathrm{y}}=5 \% \mathrm{~W}$ where $\mathrm{W}$ is the total weight of the structure. It is also useful to discuss the effect of varying these parameters on the base displacement. For this purpose a four-storey "shearbeam" superstructure model with $\mathrm{T}_{1(\mathrm{UI})}=0.4 \mathrm{secs}$ are used. Results similar to those discussed below were found by Lee ${ }^{(8)}$

First, $\mathrm{k}_{\mathrm{o}}$ and $\mathrm{F}_{\mathrm{y}}$ are varied from $2.5 \mathrm{~W} / \mathrm{m}$ to $25 \mathrm{~W} / \mathrm{m}$ and $1 \% \mathrm{~W}$ to $25 \% \mathrm{~W}$, respectively, while $\alpha \mathrm{k}_{0}$ is kept constant at $1.25 \mathrm{~W} / \mathrm{m}$. The effect of these parameter variations on the base displacement is shown in Fig.6.a. It can be seen that a BI system with a stiffer $k_{0}$ tends to minimize the base displacement. This is because to increase $\mathrm{k}_{\text {o means }}$ widening the hysteresis loop which increases the effective damping and provides a stiffer system especially at high level of $F_{Y}$. Hence it reduces the base displacement. It is also shown in Fig.6a that a linear BI system without energy dissipation capacity $\left(\alpha \mathrm{k}_{\mathrm{o}}=\mathrm{k}_{\mathrm{o}}=1.25 \mathrm{~W} / \mathrm{m}\right)$ induces a very large displacement.

Likewise, selecting too low a yield strength causes a large base displacement. In this case the effect of the initial stiffness becomes insignificant, since during the entire ground shaking the system is in the post yield condition most of the time with a narrow-band hysteresis loop having only a small amount of additional damping. on the other hand, choosing a higher yield strength to, say around $5 \% \mathrm{~W}$, leads to a significantly smaller base displacement as it basically increases the additional damping and decreases the fundamental period shift.

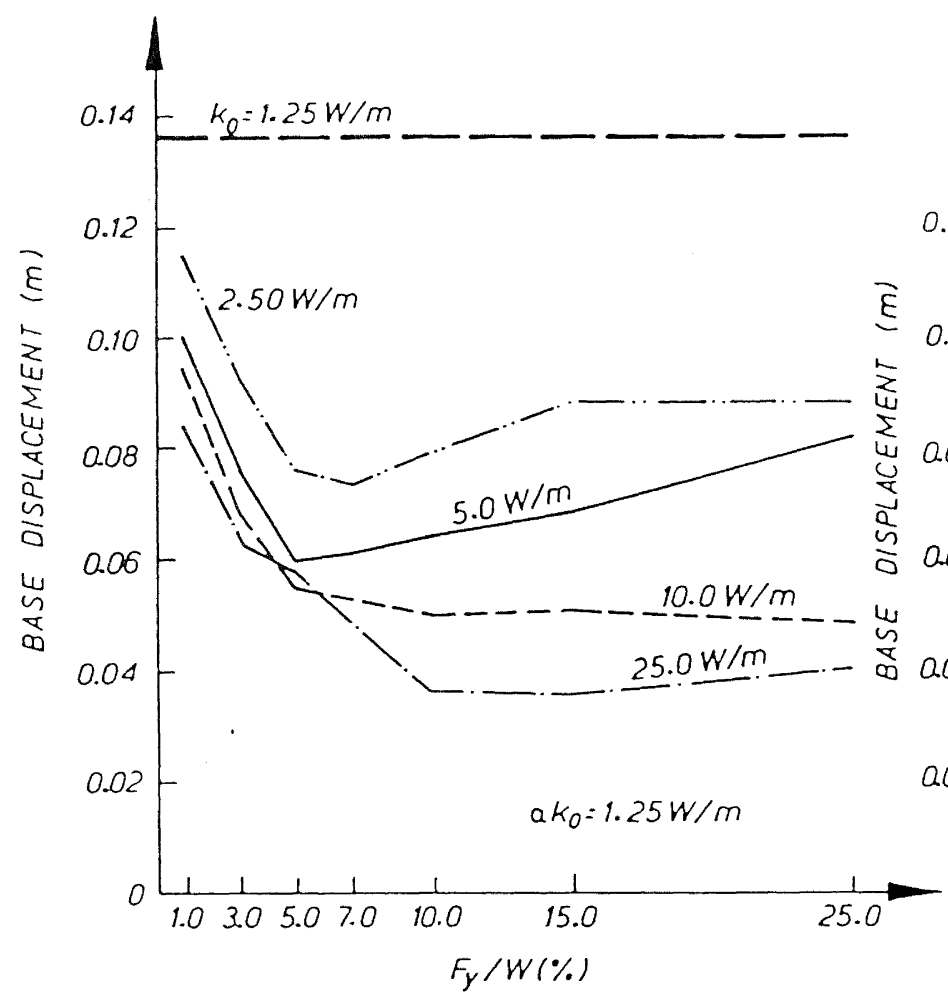

FIGURE 6a: THE EFFECT OF VARYING INITIAL STIFFNESS AND YIELD STRENGTH ON MAXIMUM BASE DISPLACEMENT
FIGURE 6b: THE EFFECT OF VARYING POST-YIELD STIFFNESS AND YIELD STRENGTH ON MAXIMUM BASE DISPLACEMENT 
For a BI system with low $\mathrm{k}_{0}$, the base displacement increases again as the yield strength becomes greater than the "optimum" point, i.e. around 5\%W. This type of BI system naturally has a small capacity for energy dissipation.

If $\alpha \mathrm{k}_{\mathrm{o}}$ and $\mathrm{F}_{\mathrm{y}}$ are now varied while $\mathrm{k}_{\mathrm{o}}$ is kept constant at $10.0 \mathrm{~W} / \mathrm{m}$, the maximum base displacement response varies as is shown in Fig.6b. In general the smaller the post-yield stiffness is the larger the base displacement. However, the effect is not so dramatic as if $\mathrm{k}_{0}$ is varied while $\alpha \mathrm{k}_{\mathrm{o}}$ is kept constant. At yield strength levels below $5 \% \mathrm{~W}$, the base displacement increases rapidly as $F_{\mathrm{y}}$ decreases especially for BI systems with a small $\alpha \mathrm{k}_{0}$. At this condition the effective stiffness becomes smaller as $\alpha \mathrm{k}$ decreases while at high levels of yield strength the effect of $F$ become insignificant, since at these levels the initial stiffness is more dominant.

The maximum base displacement of a linear BI system with lateral stiffness of 10.0 $\mathrm{W} / \mathrm{m}$ is also shown in Fig. $6 \mathrm{~b}$. As expected a relatively stiff linear $B I$ system without energy dissipation capacity is able to keep the base displacement small (c.f. a much more flexible linear BI system shown in Fig.6a), but at the expense of higher induced inertia forces as will be shown in the following subsection.

\subsection{Reduction of Inertia Forces}

From Fig.7 it can be observed that the maximum base shear of an elastic unisolated structure changes dramatically with the value of $T_{1}$ and it follows the pattern of the earthquake response spectra which, in this case, is for the El centro $1940 \mathrm{~N}-\mathrm{S}$ earthquake. For BI structures, however the variation of $\mathrm{T}_{1 \text { (UI) hardly }}$ effects the maximum base shear. This is caused by the shift of the period of the first mode, which dominates the base shear, to the plateau area of the acceleration response spectra.
Furthermore, the increased damping reduces the generated seismic forces even further and makes the base shear of BI structures insensitive to the value of $\mathrm{T}_{1(\mathrm{UI})}$.

It is obvious that a BI system will considerably reduce the base shear of short-period multistorey structures. As the superstructure becomes more flexible (say $\mathrm{T}_{1 \text { (UI) }>1.2 \text { secs) the reduction is }}$ less significant, i.e. the degree of protection diminishes for structures with longer $\mathrm{T}_{1(\mathrm{UI})}$. In this investigation a series of "shear-beam" structures mounted on a BI system with $\mathrm{K}_{0}=10.0 \mathrm{~W} / \mathrm{m}$, $\alpha=0.15$, and $\mathrm{F}_{\mathrm{y}}=5 \% \mathrm{~W}$ were used as the analytical models.

The influence of frame action on the base shear of the BI structures was found insignificant as demonstrated in Fig.8. For the entire range of evaluation $(0.2$ $\mathrm{T}_{1}(\mathrm{~s}) \leq 2.0 \mathrm{sec}$ ) the maximum base shears of BI structures with $\epsilon=0.0$ and 0.125 differ only less than $17 \%$ when compared to the maximum base shears of BI "shear-beam" structures which have $\epsilon=\infty$.

The effect of varying the BI system's parameters on the base shear is depicted in Figs. $9 \mathrm{a}$ and $9 \mathrm{~b}$. First, $\alpha \mathrm{k}_{\mathrm{s}}$ is kept constant while varying $\mathrm{k}_{0}$. Secondly, $\mathrm{k}_{0}$ is kept constant at $10.0 \mathrm{~W} / \mathrm{m}$ while $\alpha \mathrm{k}_{0}$ is varied from 0.5 to $2.5 \mathrm{~W} / \mathrm{m}$. It can be seen from Figs. $9 a$ and $9 b$ that in general the base shear reaches its minimum value when $F_{Y}$ is around 3.0 to $7.0 \% \mathrm{~W}$. In this range the $\mathrm{BI}$ system provides the maximum energy dissipation capacity and reaches its optimium performance in reducing not only the base shear, but also the base displacement.

It was found that the upper-storey shears may not be reduced by the same degree as the base shear. Fig.10 shows the lateral inertia force distribution and the lateral storey shear envelopes of an unisolated structure and BI structures which are mounted on two types of BI system. From these shear diagrams it can be seen that the upper-storey shears have a smaller

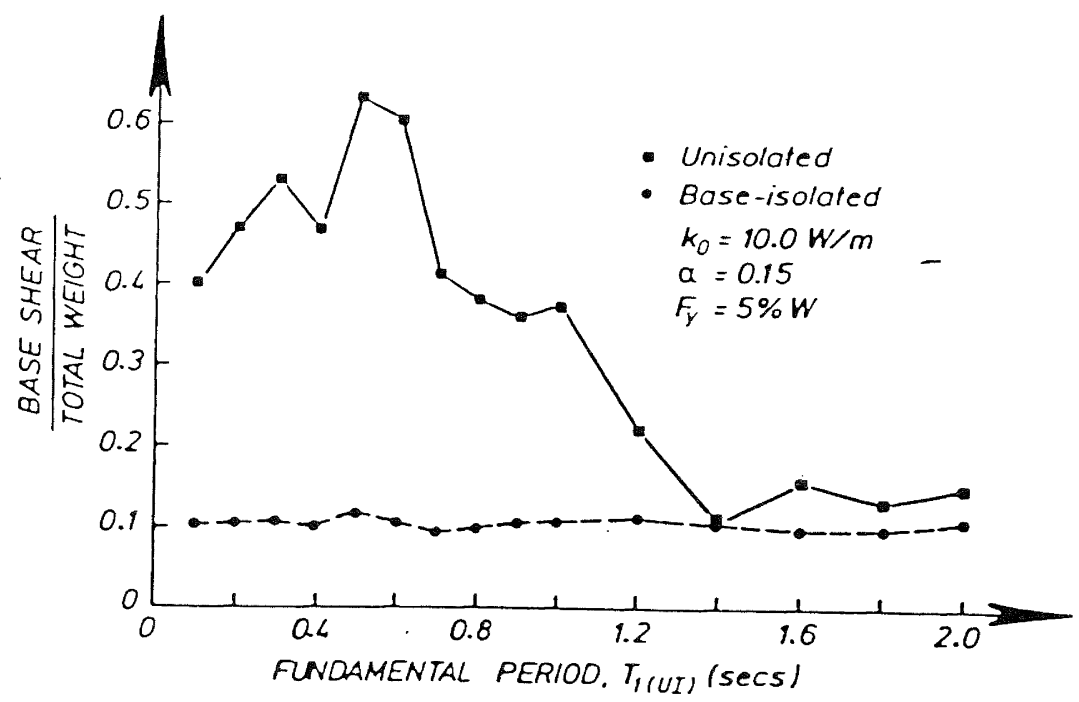

FIGURE 7: THE EFFECT OF $T_{1(U I)}$ ON MAXIMUM BASE SHEARS 


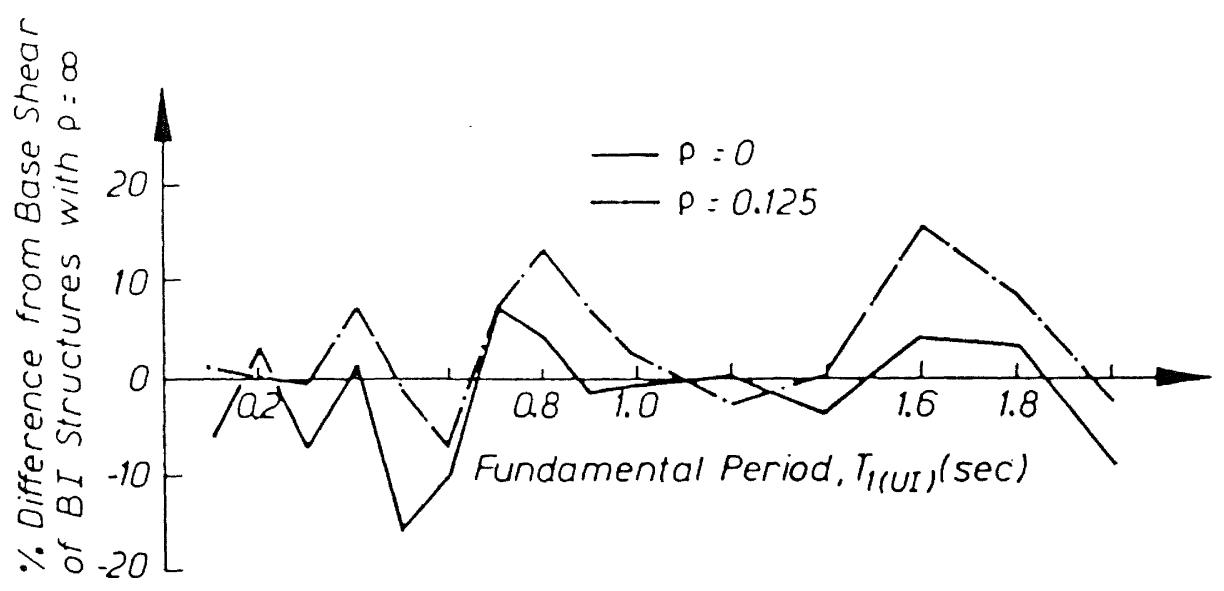

FIGURE 8: COMPARISON OF MAXIMUM BASE SHEARS OF BI STRUCTURES WITH DIFFERENT $T_{1(\mathrm{UI})}$ AND $\epsilon$

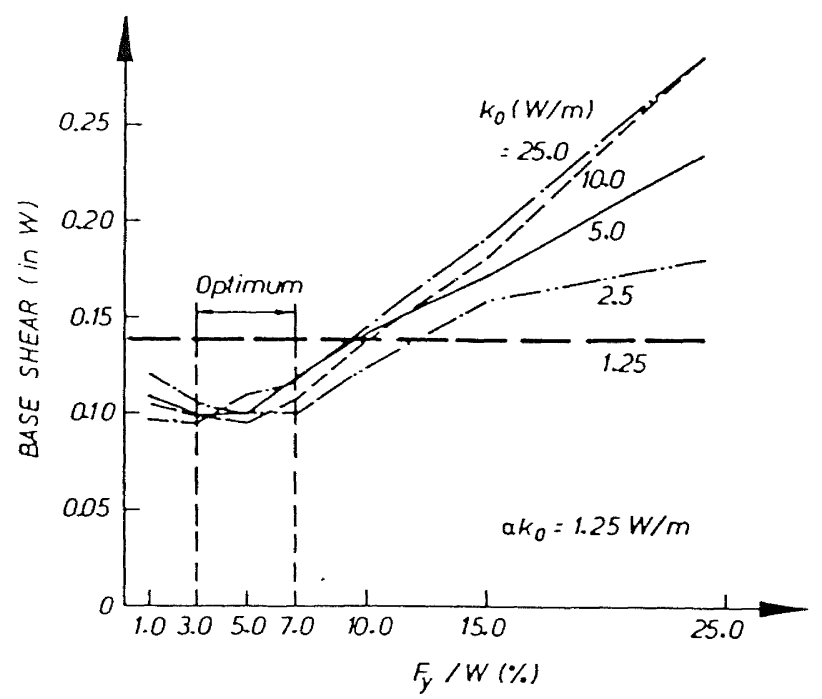

FIGURE 9a: THE EFFECT OF VARYING INITIAL STIFFNESS AND YIELD STRENGTH ON MAXIMUM BASE SHEAR

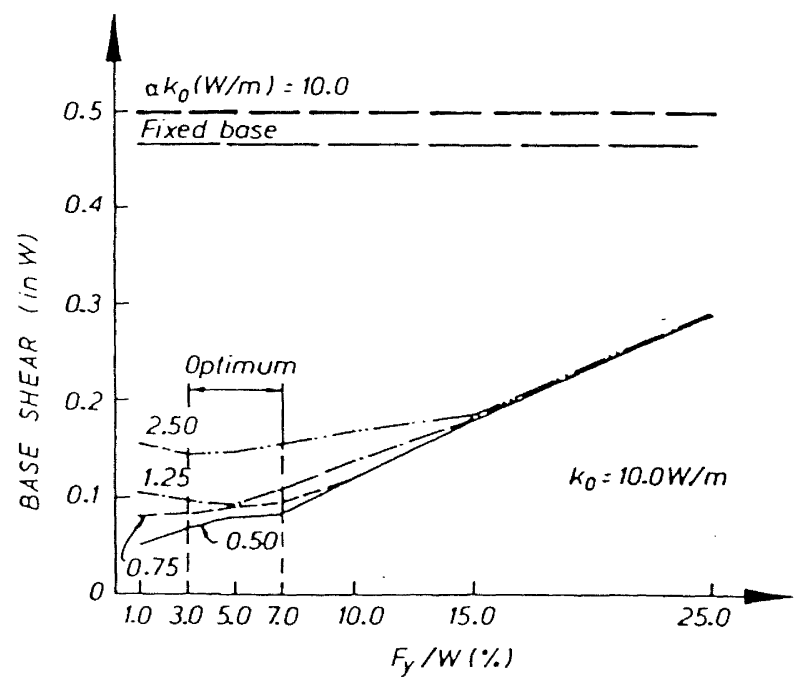

FIGURE 9b: THE EFFECT OF VARYING POST-YIELD STIFFNESS AND YIELD STRENGTH ON MAXIMUM BASE SHEAR

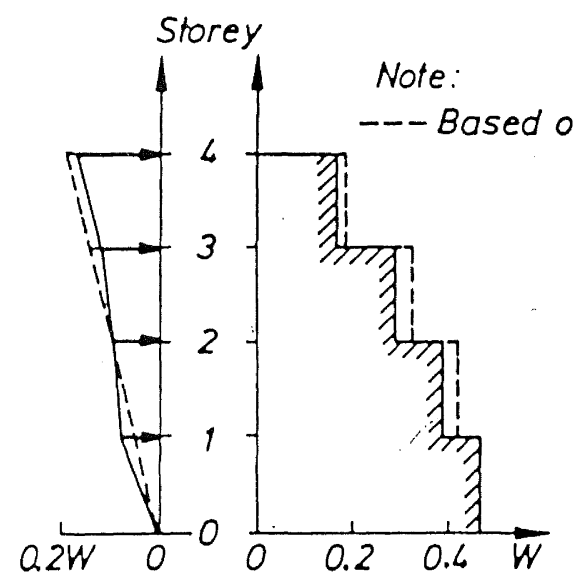

Shear Force

(a) Fixed-Base Unisolated

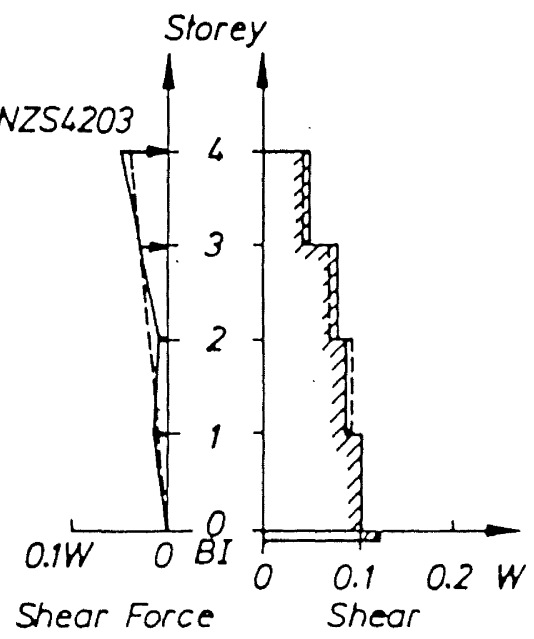

(b) Base Isolated

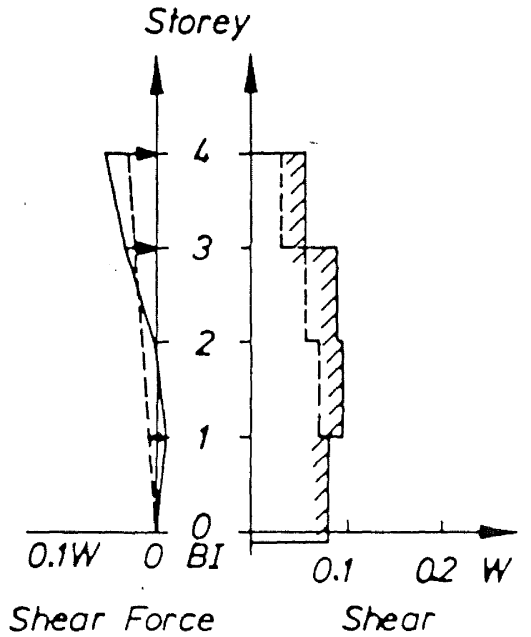

(c) Bose /soloted $\left(k_{0}=10.0 \mathrm{~W} / \mathrm{m}, \alpha k_{0}=1.5 \mathrm{~W} / \mathrm{m}, F_{y}=5 \% \mathrm{~W}\right) \quad\left(k_{0}=10.0 \mathrm{~W} / \mathrm{m}, \alpha k_{0}=0.5 \mathrm{~W} / \mathrm{m}, F_{y}=5 \% \mathrm{~W}\right)$

FIGURE 10: EOUIVALENT STATIC LATERAL FORCE DISTRIBUTIONS AND SHEAR ENVELOPES OF UNISOLATED AND BASE ISOLATED STRUCTURES 
reduction than the base shear. Hence, the equivalent static lateral force distribution recommended by the loadings codes $[9,10]$, which give a reasonable safety margin for the storey shears of unisolated structures, may underestimate the shears at the upper-storeys of BI structures especially if the BI system has a fat hysteresis loop, in this case due to a lower $\alpha \mathrm{k}_{0}$. This is discussed in section 4 .

\subsection{Reduction of Ductility Demands}

In the previous discussions the superstructure was assumed to remain elastic. Significant attenuation of the transmitted ground motion energy by a BI system enables the inertia forces to be reduced by factors of up to six. Thus it is possible to expect the superstructure to behave elastically under the designlevel earthquakes. It is important, however, to understand how a BI multistorey structure will behave under seismic load conditions beyond the design level. For this purpose the inelastic responses of a six-storey frame structure, with and without BI systems, are compared and the effect of using BI systems with a different set of parameters is also studied. The six-storey reinforced concrete moment-resistant frame was originally designed by Jury [11] based on the capacity design approach [12] and in accordance with the provision of the NZ loadings code NZS4203:1976 [13].

Inelastic time history analyses were conducted using the computer program Ruaumoko [6]. Both the unisolated and BI structures were subjected to El Centro $1940 \mathrm{~N}-\mathrm{S}$ earthquake multiplied by 1.4 so that the peak acceleration is $0.4 \mathrm{~g}$. Some researchers [3] have used this 1.4 scaled researchers [3] have used tho $1940 \mathrm{~N}-\mathrm{S}$ earthquake record to simulate an earthquake with a 450 year return period which is beyond the $\mathrm{NZ}$ Zone A's seismic design level [10].
The curvature ductility demands at beamends and column bases of the unisolated fixed-base and BI structures are shown in Fig.11. Zero indicates that no plastic hinge occurs. It is obvious that the BI structures have lower ductility demands than their fixed-base counterpart. Moreover hinge reversals are only found in some beam-ends of the BI structures whereas almost all beam-ends and column bases of the conventionally designed fixed-base structure have reversed plastic hinge rotations.

As can be seen in Fig.11, the inclusion of a BI system which has lower post-yield stiffness and greater energy dissipating capacity or fatter hysteresis loops $\left(\mathrm{k}_{\mathrm{o}}=10.0 \mathrm{~W} / \mathrm{m}, \alpha=0.05, \mathrm{~F}_{\mathrm{y}}=5 \% \mathrm{~W}\right)$ further reduces the curvature ductility demand at most beam-ends. Some members of the frame never reach their yield strengths.

The ability of a BI system to significantly reduce the ductility demand in the superstructure enables the simplification of the structural detailing and other seismic design considerations required by the more conventional approach. Therefore, a wider choice of architectural forms and structural materials would be available to the designer.

\section{LATERAL INERTIA FORCE DISTRIBUTION}

Since the late 1970 's several researchers, such as Priestley et al(14), Lee and Medland(15), and Kelly et ál(16) have studied the distribution patterns of lateral inertia forces of BI multistorey buildings with elastic superstructures. It has been realized that the shape of the lateral shear envelopes of this type of structure can vary considerably as the result of the various inertia force distribution patterns.

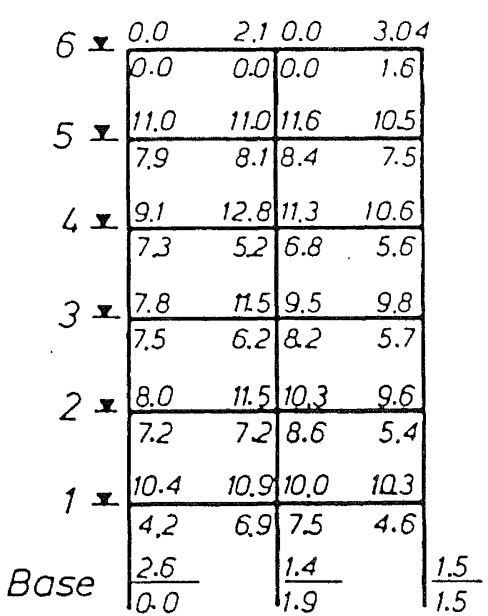

Fixed Base (Inelastic Response)

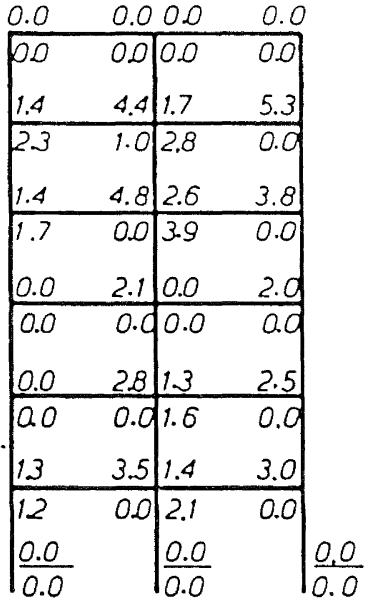

Base Isolated $\left(\begin{array}{c}k_{0}=10.0 \mathrm{~W} / \mathrm{m}, \alpha=0.15 \\ F_{y}=5 \% \mathrm{~W}\end{array}\right)$

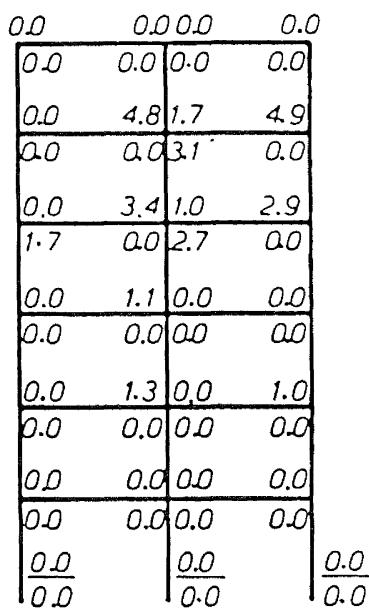

Base Isolated $\left.\begin{array}{c}\left(k_{0}=10.0 \mathrm{~W} / \mathrm{m}, \alpha=0.05\right. \\ F_{y}=5 \% \mathrm{~W}\end{array}\right)$

FIGURE 11: CURVATURE DUCTILITY DEMANDS AT BEAM ENDS AND COLUMN BASES UNDER 1.4 EL CENTRO $1940 \mathrm{~N}-\mathrm{S}$ EARTHQUAKE 
A study [4] was recently conducted at the University of Canterbury to investigate this phenomenon more thoroughly and systematically in order to propose a simple method for predicting these inertia force distributions. The results of the investigation are summarised in the following.

It was found that there are three major factors which influence the shape of the lateral storey shear envelopes of BI multistorey structures, namely :

(a) the BI system's parameters or the "fatness" of its hysteresis loops as described by the hysteresis loop ratio, $\mathrm{R}$.

(b) the fundamental period of the superstructure $\mathrm{T}_{1 \text { (UI) }}$

(c) the frame action of the superstructure as defined by its joint-rotation index, $\epsilon$.

Figure 12a illustrates the effect of varying the initial stiffness while keeping the post-yield stiffness and the yield strength level constant at $1.25 \mathrm{~W} / \mathrm{m}$ and 5\% $\mathrm{W}$, respectively. It can be seen that the difference between the base shears of a multistorey structure mounted on two different BI systems, with initial stiffness of 2.5 and $25.0 \mathrm{~W} / \mathrm{m}$ is only around $10 \%$, while at the upper levels the shears may differ as much as $94 \%$.

Low initial stiffness causes the hysteresis loop to narrow and the effect becomes similar to the one caused by a linear BI system, which deflects the input earthquake energy rather than absorbs it. As was pointed out by Kelly [16], in a vibrating linear system all modes tend to be mutually orthogonal.

In this case, all higher modes will be orthogonal to the input motion so that the transmission of high energies of input ground motion at certain frequencies, which tend to excite the higher modes, will be minimized. Therefore, the structure response becomes first mode dominant and the lateral shear envelope may even show a tendency of rigid body motion with equally distributed acceleration over the height of the superstructure. An almost straight line lateral shear envelope is depicted in Fig.12a as the effect of this type of BI system.

An increase of initial stiffness, enhances the energy absorption capacity of the BI system. The contributions of the higher modes become significant in the upper levels of the superstructure and a more bulged lateral shear envelope is encountered. A similar effect is also found as the post-yield stiffness is decreased (Fig.12b) and as the yield strength level is increased (Fig.12C).

As the results of conducting extensive analyses it was observed that there is a strong linear correlation between the hysteresis loop ratio, $\mathrm{R}$ and the exponent $p$, which is used to describe the equivalent static lateral force distribution over the height of the superstructure as expressed in the following :

$$
F_{i}=V \frac{W_{i} h_{i}^{p}}{\Sigma W_{i} h_{i}^{p}}
$$

where $V$ is the base shear, $w_{i}$ and $h_{i}$ are the floor weight and the floor height, respectively.

In this section the correlations between these two factors for a wide range of BI structures, i.e. with $\mathrm{T}_{1 \text { (UI) }}=0.2,0.4$, 0.8 seconds and $\epsilon=0.0,0.125, \infty$, are shown in Table 1 or Fig.13. These correlations are based on the linear regression analyses [17] of data for the two variables, i.e. $R$ and $p$. The range of the most likely used BI systems is covered by incorporating isolation systems with R from 0.1 (thin loop) to 0.6 (fat loop). BI structures which have $\mathrm{T}_{1}$ (fI equal to 0.8 secs but with $\mathrm{R} \geq 0.4$ or $\mathrm{T}_{1 \text { (UI) larger }}$ than 0.8 secs are not included since their shear envelopes become difficult to approximate using this approach.

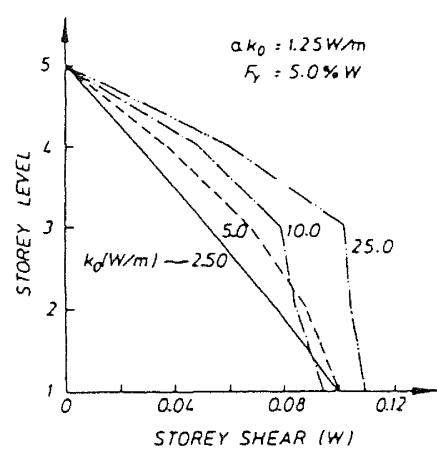

a. Varying initial stiffness

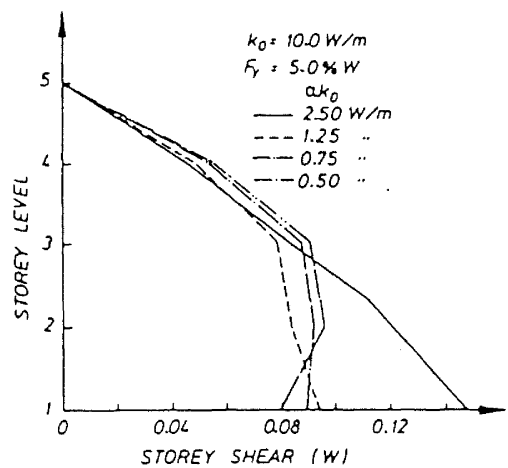

b. Varying post-yield stiffness

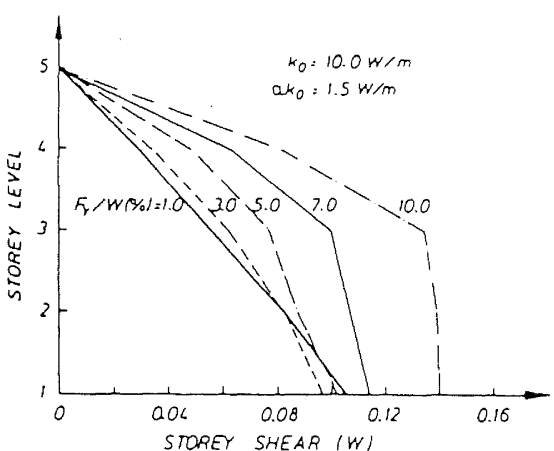

c. Varying yield strength

FIGURE 12: THE EFFECT OF VARYING BI SYSTEM PARAMETERS ON LATERAL STOREY SHEARS 
Table 1: Correlations between the Hysteresis Loop Ratio and the Exponent p

\begin{tabular}{||c|c|c|c|c|c|}
\hline \multirow{2}{*}{$\mathrm{T}_{1(\mathrm{UI})}$} & \multicolumn{5}{|c|}{ Linear Regression Analysis } \\
\cline { 2 - 6 } & \multicolumn{1}{|c|}{$\rho$} & $\mathrm{A}$ & $\mathrm{B}$ & $\mathrm{r}$ & $\mathrm{s}_{\mathrm{y} \mid \mathrm{x}}$ \\
\hline \multirow{2}{*}{0.2} & 0.000 & -0.7339 & 4.7912 & 0.87 & 0.39 \\
& 0.125 & -0.7902 & 4.6367 & 0.80 & 0.50 \\
& $\infty$ & -0.4352 & 2.8246 & 0.71 & 0.41 \\
0.4 & 0.000 & -0.5517 & 6.0054 & 0.93 & 0.31 \\
& 0.125 & -1.0670 & 8.1152 & 0.89 & 0.49 \\
& $\infty$ & -0.8483 & 6.7600 & 0.85 & 0.40 \\
0.8 & 0.000 & -0.2475 & 9.3684 & 0.91 & 0.37 \\
& 0.125 & 0.0081 & 7.1251 & 0.70 & 0.62 \\
& $\infty$ & -0.4347 & 8.5817 & 0.88 & 0.42 \\
& & & & & \\
\hline
\end{tabular}

Note: Exponent $\mathrm{p}=\mathrm{A}+\mathrm{BR}$

$$
\begin{array}{rl}
\text { Exponent } \mathrm{p} & \mathrm{A}+\mathrm{BR} \\
\mathrm{R} & =\text { Hysteresis Loop Ratio } \\
r & =\text { Correlation Coefficient }(\sim 1.0 \text { implies a } \\
\mathrm{s}_{\mathrm{Y} \mid \mathrm{x}} & =\text { confectly linear correlation) }
\end{array}
$$

As shown in Table 1, the lowest correlation coefficient, $r$ is found to be 0.70 while the average value of $r$ is 0.84 . The corresponding conditional standard deviations, $s_{y} \mid x$ are also listed in Table 1. The total samples considered in this observation are 36,34 , and 24 cases for $\mathrm{BI}$ structures with $\mathrm{T}_{1}$, $=0.2,0.4$ and 0.8 seconds, respectively. The range of the BI systems' yield strengths is 3.0 to $7.0 \% \mathrm{~W}$.

Fig.13 shows the values of the exponent $p$ for different $\epsilon$ diverge as $R$ increases. It can also be seen that the slope of the correlation lines becomes steeper for BI structures with longer $\mathrm{T}_{1 \text { (UI) }}$.

As the value of exponent $p$ increases, the lateral shear envelope becomes more bulged which indicates that the higher mode contributions to the upper storey shears have become more significant. At $\mathrm{T}_{1}$. 0.2 and 0.8 seconds, BI structures (With $\epsilon=0.0$ tend to have larger $p$ and therefore more bulged shear envelopes than their counterparts with $\epsilon=0.125$ and $\epsilon=\infty$. This trend however, is not found for $B I$ structures with $\mathrm{T}_{1(\mathrm{UI})}=0.4$ secs. Since the modal contributions to the storey shears are also dependent on the likely irregular shape of the earthquake spectral acceleration as well as being affected by the inelastic behaviour of the BI system, the above phenomenon cannot be approximately evaluated using only their initial and pseudo post-yield linear modal properties [4].

In spite of this, the strong correlation

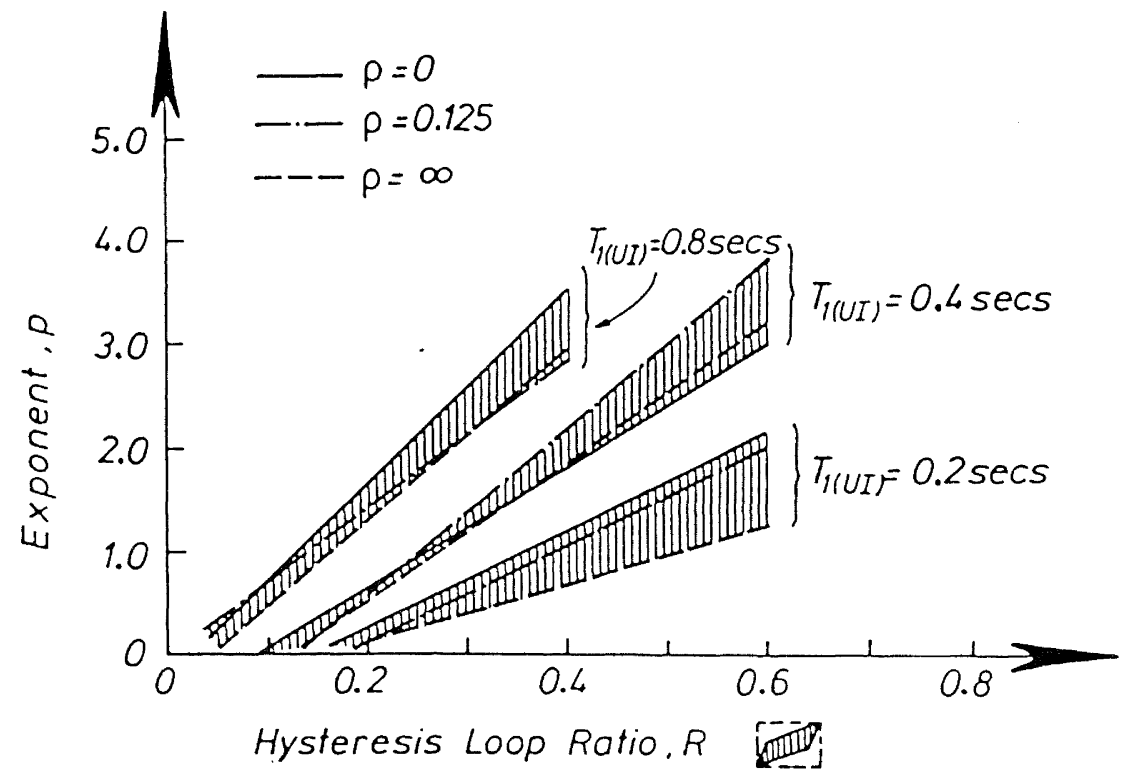

FIGURE 13: CORRELATIONS BETWEEN THE HYSTERESIS LOOP RATIO, $R$ AND THE EXPONENT P 
between $R$ and $p$ is very useful in providing the designer with a "quick" guidance in order to be able to predict the likely equivalent static lateral force distribution for a particular BI structure 5].

5. THE INFLUENCE OF GROUND MOTION

To investigate the behaviour of BI multistorey structures under different ground motions, six real earthquake records and one artifically generated earthquake record were used. These earthquakes can be categorized into two groups of ground motion. The first group, which have acceleration response spectra which diminish at longer natural periods consists of El Centro $1940 \mathrm{~N}-\mathrm{S}, \mathrm{El}$ Centro 1979 N-S, Parkfield 1966 N65E, Pacoima Dam 1971 S16E and the Artificial A1 [18]. TWo other earthquake records, i.e. Bucharest $1977 \mathrm{~N}-\mathrm{S}$ and Mexico 1985 at the SCT site belong to the second group which is often used in attempts to discredit the benefits of displacement-dependent BI systems. Previous analyses using the El Centro 1940 $\mathrm{N}-\mathrm{S}$ earthquake record were repeated using the other earthquake records. Only some highlights of the results are reported here.

Figure 14 shows the correlations between the hysteresis loop ratio, $R$ and the exponent $p$ used in Eq.5 for BI structures with $T_{1 \text { UI }}=0.8$ secs subjected to group ground motions. It can be seen from this figure that the correlations between $R$ and $p$ are earthquake dependent. Similar results for other "shear-beam" structures with different $\mathrm{T}_{1(\mathrm{UI})}$ are reported elsewhere [4].

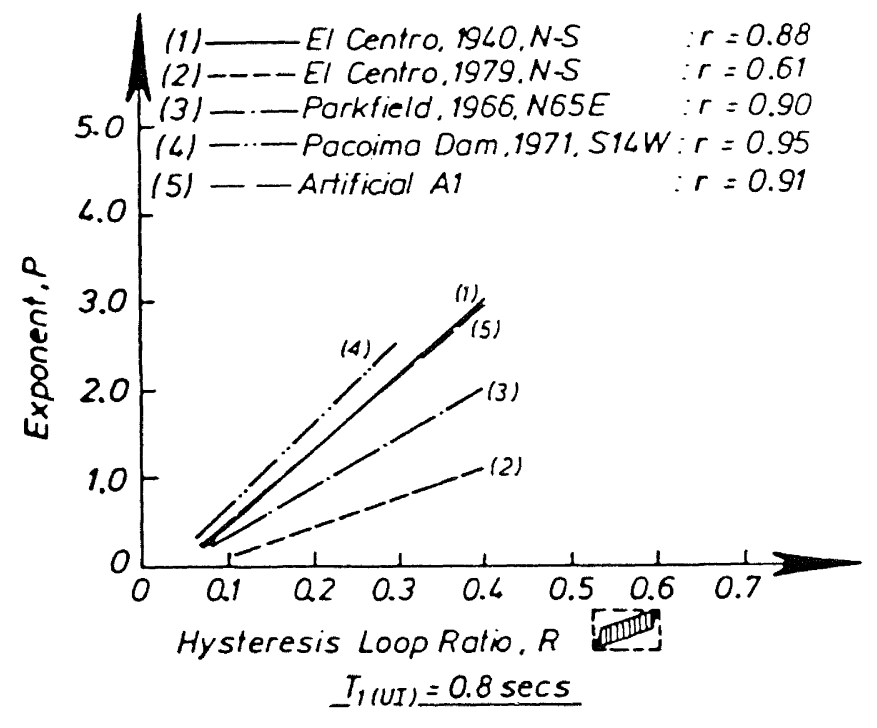

FIGURE 14: RELATIONSHIPS BETWEEN $R$ AND $\epsilon$ FOR BI "SHEAR-BEAM" STRUCTURES WITH $T_{1}$ UI $=0.8$ SECS UNDER VARIOUS EARTHQUARES

The correlations between the hysteresis loop ratio, $R$ and the exponent $p$ of $B I$ structures subjected to Bucharest $1977 \mathrm{~N}-\mathrm{S}$ and Mexico 1985 at the SCT site earthquakes are not evaluated since the implementation of displacement-dependent BI systems for this second group ground motion may not reduce the lateral storey shears. Fig.15 demonstrates this phenomenon and contrasts the effects of a BI system on the lateral storey shear envelopes of structures subjected to El Centro $1940 \mathrm{~N}-\mathrm{S}$, Bucharest $1977 \mathrm{~N}-\mathrm{S}$, and Mexico 1985 earthquakes. Three types of

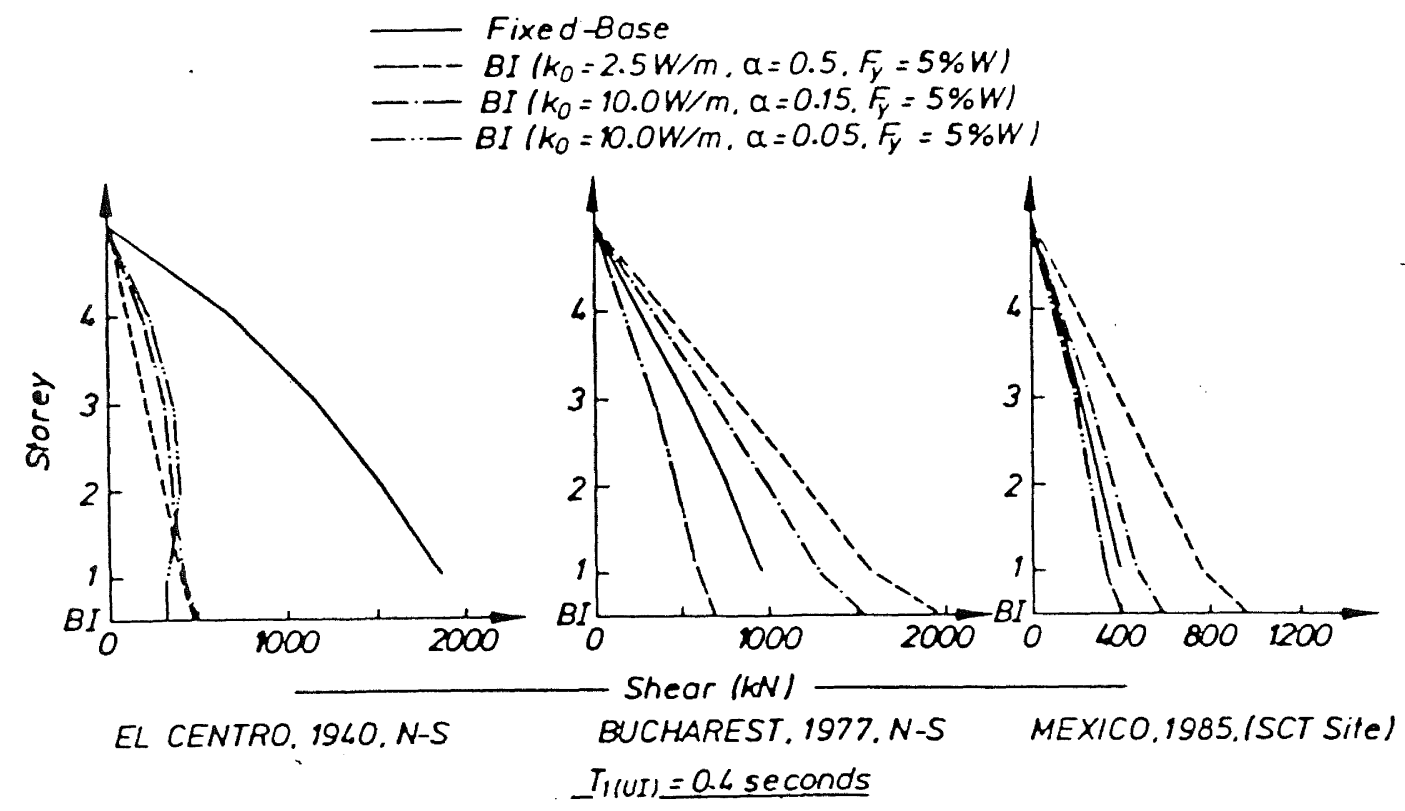

FIGURE 15: THE EFFECTS OF VARIOUS BI SYSTEMS ON THE LATERAL STOREY SHEARS OF STRUCTURES SUBJECTED TO DIFFERENT TYPES OF EARTHQUAKE 
BI system with thin $\left(\mathrm{k}_{0}=2.5 \mathrm{~W} / \mathrm{m}, \alpha=0.5\right.$, $\left.\mathrm{F}_{\mathrm{y}}=5 \% \mathrm{~W}\right)$, moderate $\left(\mathrm{k}_{\mathrm{o}}=10.0 \mathrm{~W} / \mathrm{m}, \alpha=\right.$ $\left.0.15, \mathrm{~F}_{\mathrm{Y}}=5 \% \mathrm{~W}\right)$, and fat $\left(\mathrm{k}_{\mathrm{O}}=10.0 \mathrm{~W} / \mathrm{m}, \alpha\right.$ $=0.05, \mathrm{~F}_{\mathrm{Y}}=5 \% \mathrm{~W}$ ) hysteresis loops are considered. It can be seen in Fig.15 that for ground motions which have peak spectral accelerations in the short period region, such as El centro $1940 \mathrm{~N}-\mathrm{S}$ earthquake, the inclusion of any type of BI system can cause significant reduction of the lateral storey shears. In contrast, the Bucharest $1977 \mathrm{~N}-\mathrm{S}$ and Mexico 1985 (SCT sites) earthquakes, which have peak spectral accelerations at about 1.4 and 2.0 seconds respectively, increase the lateral storey shears with the inclusion of a displacement-dependent BI system. As shown in Fig.15, structures mounted on thin and moderately fat hysteresis loops have larger storey shears than their fixed-base counterparts. Some reductions can only be achieved by using BI systems with large energy dissipation capacities. As expected, these reductions are still not so dramatic as observed in the El Centro $1940 \mathrm{~N}-\mathrm{S}$ earthquake. Any displacement-dependent BI system tends to lengthen the fundamental period of the structure and thus shifts it into a more dominant energy region of the Bucharest and Mexico city type earthquakes. Therefore the large energy dissipation capabilities become less effective. For this particular case it is desirable to use a BI system which does not lengthen the fundamental period such as viscoelastic dampers [11].

\section{CONCLUSIONS}

1. The benefits of implementing a BI system have been demonstrated. Due to the inclusion of a BI system, the inertia forces and the interstorey drifts of a multistorey structure can be significantly reduced. As a result, the superstructure can be designed to behave elastically under design-level earthquakes. The much smaller interstorey drifts prevent the early occurence of non-structural damage during moderate ground motions.

2. Under earthquakes beyond the designlevel excitations, a superstructure monted on a BI system shows many fewer plastic hinges and has much lower ductility demands when compared with a conventionally designed ductile structure. The structural members of BI multistorey structures may not necessarily be designed to full ductility requirements and therefore the isolation technique widens the choice of architectural form and structural materials.

3. BI systems with low effective stiffness may cause significant lengthening of the fundamental period, especially for very stiff superstructures. Under earthquakes with spectral accelerations that diminish at longer periods this fundamental period shift causes considerable reduction in inertia forces. However, without sufficient additional hysteretic damping, an excessive base displacement may occur.

4. Multistorey structures mounted on a BI system with a small energy dissipation capacity or thin hysteresis loops are strongly first mode dominated. In this case the equivalent lateral force are almost uniformly distributed over the entire height of the superstructure. In contrast, if the BI system has a great energy dissipation capacity, indicated by a high hysteresis loop ratio $R$, the contributions of the higher modes become more significant, especially in the upper-storeys, and causes the lateral shear envelope to be more bulged. As strong linear correlation was found between the hysteresis loop ratio $\mathrm{R}$ and the shape of the lateral shear envelope. This correlation is dependent upon $\mathrm{T}_{1 \text { (UI)' }}$ the beam-to-column stiffness ratio, $\epsilon$ and the characteristics of the ground motion.

5. For sites with ground motions which have peak spectral acceleration in longer periods the inclusion of a BI system may shift the fundamental period of the structure into that of a more dominant earthquake response. However, it seems possible to reduce the transmitted energy of this type of earthquake into the superstructure by using systems that provide large amounts of additional damping without increasing the fundamental period of the structure.

\section{ACKNOWLEDGEMENTS}

The research reported in this paper was conducted in the Department of Civil Engineering, University of Canterbury, New Zealand, by the first author under the supervision of the second author. The financial assistance provided by the Ministry of Works and Development, New Zealand is gratefully acknowledged.

\section{REFERENCES}

1. MEGGET, L.M., Analysis and Design of a Base-Isolated Reinforced Concrete Frame Building, Bull. of NZNSEE, Vol.11, No.4, pp.245-254, 1978.

2. BROADMAN, P.R., WOOD, B.J., and CARR, A.J., Union House - A Cróss Brached Structure with Energy Dissipators, Bull. of the NZNSEE, Vol.16, No.2, pp. 83-97, 1983

3. CHARLESON, A.W., WRIGHT, P.D., and SKINNER, R.I., Wellington Central police station - Base Isolation of an Essential Facility, Proc.Pacific Conference on Earthquake Engineering, Vol.2, pp.377-388, 1987.

4. ANDRIONO, T., Seismic Resistant Design of Base Isolated Multistorey structures, PhD Thesis, University of Canterbury, 1989. 
5. ANDRIONO, T. and CARR, A.J., A Simplified Earthquake Resistant Design Method for Base Isolated Multistorey structures, Bull. of the NZNSEE, Vol. 24, No. 3, pp238-250, Sept. 1991

6. CARR, A.J. "Ruaumoko", Computer program Library, Department of Civil Engineering, University of Canterbury, 1986.

7. BLUME, J.A., Dynamic Characteristics of Multistorey Buildings, Journal of the Structural Division, ASCE, Vol.94, No.ST2, pp.337-402, 1968.

8. LEE, D.M., The Effect of Base Isolation on Multistorey Shear Structures, PhD Thesis, Department of Theoretical and Applied Mechanics, University of Auckland, 1978.

9. Code of Practice for General Structural Design and Design Loadings for Buildings, NZS4203:1984, Standard Association of New Zealand (SANZ), 1984 .

10. Draft Replacement for Code of Practice for General structural Design and Design Loadings for Buildings, DZ4203, SANZ, 1986.

11. JURY, R.D., Seismic Load Demands of Columns of Reinforced Concrete Multistorey Frames, Research Report 78-12, Department of Civil Engineering, University of Canterbury, 1978.

12. PARK, R. and PAULAY, T., Reinforced Concrete structures, John Wiley and Sons, pp.600-607, 1975.
13. Code of Practice for General Structural Design and Design Loadings for Buildings, NZS4203:1976, SANZ, 1976.

14. PRIESTLEY, M.J.N., CROSBIE, R.L., CARR, A.J., Seismic Force in Base Isolated Masonry Structures, Bull. of the NZNSEE, Vol. 10, No.2, pp.55-68, 1977 .

15. LEE, D.M. and MEDLAND, I.C., Estimation of Base Isolated Structure Responses, Bull. of the NZNSEE, Vol.11, No.4, pp.234-244, 1978.

16. KELLY, J.M., EIDINGER, J.M. and DERHAM, C.J., A Practical Soft Storey Earthquake Isolation system, Report No.UCB/EERC-77/27, EERC, University of California, Berkeley, 1977.

17. ANG, A.H.S. and TANG, W.H., Probability Concepts in Engineering Planning and Design, Vol.1 - Basic Principles, John Wiley and Sons, Inc., 1975 .

18. JENNINGS, P.C., et al., simulated Earthquake Motions, Earthquake Engineering Research Laboratory, California Institute of Technology, 1968 .

19. Research on Viscoelastic Dampers for Seismic Applications, NCEER Bulletin of April 1988, pp.2-4 